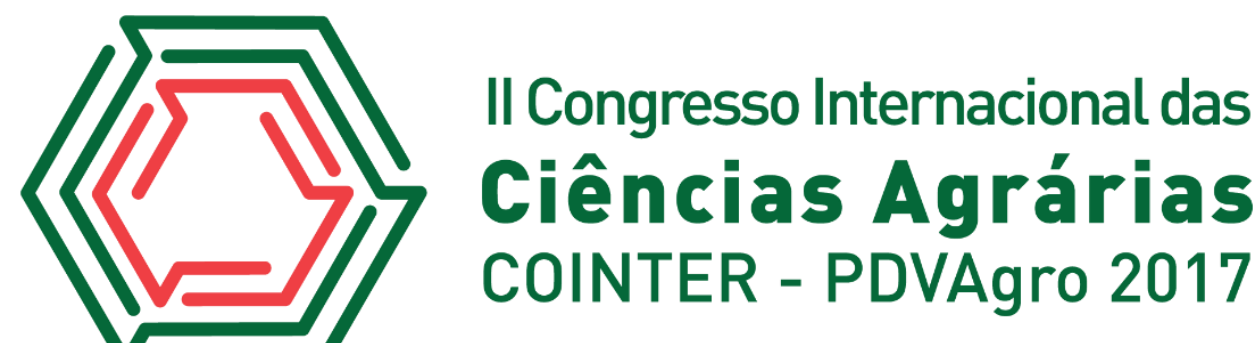

\section{LEVANTAMENTO DOS ASPECTOS PRODUTIVOS DE HORTAS COMUNITÁRIAS DE SÃO RAIMUNDO DAS MANGABEIRAS - MA}

\author{
Apresentação: Pôster
}

João Verissimo Batista Neto ${ }^{1}$; Débora Janine Silva Gonçalves ${ }^{2}$; Maiany Gonçalves de Carvalho $^{3}$ Cristiane Nunes da Conceição ${ }^{4}$; Ana Régia Alves de Araújo ${ }^{5}$

\section{Introdução}

A horticultura brasileira antes caracterizada pela informalidade possui hoje expressiva importância no que se refere à geração de renda e emprego, sendo uma atividade extremamente diversificada, com base de mão de obra familiar, o que para Faulin e Azevedo (2003) contribui para o fortalecimento e garantia da sustentabilidade da produção agrícola de pequenos produtores.

A alta perecibilidade das hortaliças, somada a fatores como falta de conhecimento técnico, deficiência em infraestrutura e manuseio inadequado dos agricultores são fatores decisivos para os níveis insatisfatórios de produtividade e perdas elevadas, o que torna a produção final insuficiente para atender a demanda social, comprometendo assim, a sustentabilidade do sistema familiar.

Para Neves (2005) a produção alimentícia deve ter como base estrutural a segurança, produtividade e sua capacidade de nutrição. Para tais fundamentos é necessário um programa de controle e manejo que venha regularizar todo o processo produtivo a fim de torná-lo sustentável, viável e rentável.

Neste contexto, portanto, entende-se que é necessário trabalhar conhecimento de técnicas agrícolas que buscam a produção com eficiência econômica, com uso sustentável dos recursos naturais e ao mesmo tempo aumento da produção em quantidade e qualidade a fim de alcançar o desenvolvimento com sustentabilidade da produção de hortaliças de pequenos produtores. Objetivou-se investigar aspectos produtivos e de manejo das hortas.

\footnotetext{
${ }^{1}$ Agronomia, Instituto Federal de Educação, Ciência e Tecnologia do Maranhão, verissimo316@gmail.com

${ }^{2}$ Agronomia, Instituto Federal de Educação, Ciência e Tecnologia do Maranhão, deboragoncalves94@gmail.com

${ }^{3}$ Mestra, Instituto Federal de Educação, Ciência e Tecnologia do Maranhão, maiany.carvalho@ifma.edu.br

${ }^{4}$ Agronomia, Instituto Federal de Educação, Ciência e Tecnologia do Maranhão, cristianenunes2996@gmail.com

${ }^{5}$ Mestra, Instituto Federal de Educação, Ciência e Tecnologia do Maranhão, ana.alves@ifma.edu.br
} 


\section{Fundamentação Teórica}

Conceitualmente Roese (2003) traz a agricultura urbana como aquela realizada em pequenas áreas dentro de uma cidade, ou no seu entorno (peri-urbana), e destinada à produção de cultivos para utilização e consumo da família ou para a venda em pequena escala. Esta modalidade pode ser realizada com diversificadas atividades de acordo com as categorias de produtos cultivados.

Assim, é válido ressaltar ainda, que uma das técnicas de Agricultura Urbana e Peri-urbana mais difundidas no Brasil referem-se às hortas. Estas possuem várias tipologias quanto à exploração, apresentando objetivos e organização diferenciada. Com o objetivo social, podem-se citar as hortas conduzidas pela comunidade, mais conhecidas como hortas comunitárias.

Para Arruda (2006), são hortas cultivadas em conjunto por grupos de famílias ou pessoas de uma comunidade, através de cooperativas de produção, sendo responsáveis pelo gerenciamento da produção, ou seja, a gestão incorpora a participação ativa da comunidade, responsável pela administração e manejo das mesmas.

\section{Metodologia}

O diagnóstico foi realizado através de visitas às hortas comunitárias do município de São Raimundo das Mangabeiras, com aplicação de questionário estruturado e semi-estruturado aos produtores. Na investigação ainda foi utilizado ainda o método observacional com acompanhamento do dia-a-dia da produção de hortaliças e com anotações das práticas desenvolvidas para análises e comparação com recomendações técnicas.

Dessa forma o método de pesquisa trabalhado, quanto às bases lógicas da investigação, compreende o método indutivo, que segundo Gil (1999) é o método onde, parte-se da observação de fatos ou fenômenos cujas causas se deseja conhecer e posteriormente compara-os com a finalidade de descobrir as relações existentes entres eles.

Realizou-se análises de solo, coletou-se em cada horta 1 amostra composta, visto que as áreas não ultrapassam 1 hectare. Para compor a amostra composta coletou-se aleatoriamente solo em 20 pontos (amostras simples) a uma profundidade de $0-20 \mathrm{~cm}$ com trado calador.

Foram colhidas amostras dos reservatórios das hortas e analisou-se basicamente a presença de coliformes totais, visto que este é um indicador alternativo para averiguar a contaminação da água. 


\section{Resultados e Discussões}

$\mathrm{Na}$ primeira etapa da pesquisa, para o diagnóstico, foram aplicados questionários com 26 (vinte e seis) agricultores das três hortas comunitárias do município, todas localizadas na zona urbana: Horta São Francisco com $2.368 \mathrm{~m}^{2}$, Horta São José com $1.067 \mathrm{~m}^{2}$ e Horta do Nazaré com $945 \mathrm{~m}^{2}$. Dentre as principais hortaliças produzidas, destacam-se as folhosas como alface, coentro, cebolinha, couve e rúcula, seguida das hortaliças-frutos como pepino, pimentão, tomate, berinjela, jiló e quiabo.

Considerando as atividades de manejo, verificou-se que os horticultores nunca realizaram análise de solo, o que implica no desconhecimento das propriedades e características do solo, podendo ainda contribuir para o uso indiscriminado de corretivos e adubos químicos e/ou orgânicos no solo.

Verificou-se acidez muito baixa para os solos das hortas 1 e 2, e baixa para os solos da horta 3, estando assim os valores de $\mathrm{pH}$ adequados, pois conforme Branco e Alcântara (2012) a faixa adequada para a maioria das hortaliças varia de 6,0 a 6,5. Em relação à horta 3, não há necessidade de calagem, visto que os níveis de Cálcio e Magnésio estão satisfatórios e o teor de Al tóxico está zerado.

Tabela 1: Resultados das análises de solo

\begin{tabular}{lcrcccccc}
\hline Horta & $\mathbf{p H}$ & \multicolumn{1}{c}{$\mathbf{P}$} & $\mathbf{K}$ & $\mathbf{C a}$ & $\mathbf{M g}$ & $\mathbf{A l}$ & $\mathbf{H}+\mathbf{L}$ & $\mathbf{M . O}$. \\
\cline { 3 - 9 } & & $\mathrm{mg} / \mathrm{dm}^{3}$ & & & ${\mathrm{cmol} / \mathrm{dm}^{3}}$ & & & $\mathrm{~g} / \mathrm{kg}$ \\
\hline Horta 1 & 6,1 & 220,8 & 0,71 & 4,49 & 1,73 & 0 & 0,49 & 29,3 \\
Horta 2 & 6,2 & 237,9 & 1,2 & 6,2 & 2,37 & 0 & 0,61 & 35,3 \\
Horta 3 & 5,6 & 213,2 & 0,82 & 4,07 & 1,62 & 0 & 0,69 & 29,5 \\
\hline
\end{tabular}

No que diz respeito ao fósforo, os valores expressos nas análises indicam teores elevados para o elemento, com uma média de $224 \mathrm{mg} / \mathrm{dm}^{3}$, fato que pode ser explicado parcialmente pelo uso indiscriminado de esterco bovino ao longo dos contínuos cultivos. Neste caso, podendo se tornar um fator limitante para o crescimento vegetal das hortaliças. O potássio foi apresentado nas análises com teores altos $\left(0,71\right.$ a $\left.1,2 \mathrm{cmol} / \mathrm{dm}^{3}\right)$. Esta alta disponibilidade de potássio pode ocasionar insuficiência na absorção de Ca e Mg pelas hortaliças. Por sua vez, os teores de Cálcio e Magnésio se mostram adequados. 
Por fim, quando se analisa a matéria orgânica verifica-se teores elevados, sendo justificado pela aplicação de compostos orgânicos, incorporação de restos culturais e utilização de esterco de animais, o que contribui para a melhoria das condições do solo para o cultivo de hortaliças.

Aproximadamente $27 \%$ dos agricultores afirmaram utilizar Barrage (Cypermethrin) no controle de formigas. Tal condição reflete um ponto crítico da cadeia que é o uso de produtos sem registro para as hortaliças, uma vez que o mesmo possui uso veterinário, com atividade carrapaticida. Este fato é um grande problema da horticultura em geral, tornando impossível garantir a segurança de um alimento quando ele apresenta resíduos de um produto. De uma maneira geral, as hortas enfrentam grandes problemas de manejo, dificuldades estas agravadas por um fator principal que é a falta de conhecimento técnico, mais de $80 \%$ dos entrevistados afirmaram que a principal dificuldade encontrada no processo produtivo se refere em obter assistência técnica

Em todas as hortas, a água apresentou coliformes totais, não satisfazendo aos padrões microbiológicos para tal uso, o que permite inferir qualidade insatisfatória e assim uma possível fonte direta de contaminação das hortaliças e veículo de transmissão de doenças aos consumidores.

Ainda quanto ao manejo do solo, verificou-se que alguns horticultores utilizam esterco fresco ou realizam erroneamente o curtimento, em até dez dias, sendo que recomendado é um período de seis meses para a estabilização do esterco. Conforme EMBRAPA (2005), fatos estes que representa um grande risco de contaminação para as hortaliças consumidas cruas. Outro hábito que participa de forma negativa é o curtimento do esterco próximo aos canteiros. No processo de curtimento, fluidos são liberados, estes sendo fontes potenciais de contaminação microbiológica (patógenos) e contaminação química (nitratos e ureia).

Para EMBRAPA (2004), os depósitos de esterco devem se situar preferencialmente nas áreas mais baixas do terreno, sendo revestidos de plástico ou argila ou pode-se também usar áreas cimentadas e com proteção lateral para evitar a lixiviação para as águas subterrâneas ou o escorrimento para as áreas de produção ou fontes de água.

Sobre pragas e doenças vale destacar que nenhum manejo é realizado pelos horticultores, verificando o controle mecânico de pragas, que consiste na catação manual e/ou arranquio da planta, e a aplicação de barrage, conforme já relatado. Diante desta realidade, tem-se mais uma dificuldade da produção que é a ausência de assistência técnica para um controle químico, ou preferencialmente para o controle alternativo (defensivo orgânico). 


\section{Conclusões}

Conclui-se que os gargalos apontados refletem basicamente o desconhecimento dos métodos agrícolas e a ausência de assistência técnica para o acompanhamento das atividades e recomendações técnicas.

Embora as hortas comunitárias estejam voltadas para a produção de alimentos para o autoconsumo da família, é interessante a mudança do paradigma. Uma vez que a concretização dessas unidades produtivas contribui para a complementação de renda, ocupação da mão de obra ociosa, melhoria do padrão alimentar e acima de tudo para a inclusão social.

\section{Referências}

ARRUDA, J. Agricultura urbana e peri-urbana em Campinas/SP: análise do programa de hortas comunitárias como subsídio para políticas públicas. 2006. 162 f. Dissertação (mestrado em Engenharia Agrícola) - Universidade Estadual de Campinas, Campinas 2006. Disponível em: < http://repositorio.unicamp.br/jspui/bitstream/REPOSIP/257090/1/Arruda_Juliana_M.pdf>.

Acessado em: 10/09/2017.

BRANCO, M. C.; ALCÂNTARA, F. A. Hortas Comunitárias: experiências do Brasil e dos Estados Unidos, v. 3. Brasília: EMBRAPA Hortaliças, 2012.

EMPRESA BRASILEIRA DE PESQUISA AGROPECUÁRIA. Boas práticas agrícolas para produção de alimentos seguros no campo: cuidados até a colheita. Brasília: Embrapa Transferência de Tecnologia, 2005.

EMPRESA BRASILEIRA DE PESQUISA AGROPECUÁRIA. Manual de Boas Práticas Agrícolas e Sistema APPCC. Projeto PAS campo. Convênio CNI/SENAI/SEBRAE/EMBRAPA. Brasília: EMBRAPA/SEDE, 2004.

NEVES, M. C. P. Boas Práticas agrícolas e a produção orgânica de frutas, legumes e verduras. Seropédica: EMBRAPA Agrobiologia, 2005.

FAULIN, E. J; AZEVEDO, P. F. Distribuição de hortaliças na Agricultura familiar: uma análise das transações. Informações Econômicas, SP, v.33, n.11, nov. 2003. Disponível em: < http://www.iea.sp.gov.br/out/publicacoes/pdf/ tec3-1103.pdf>. Acessado em: 10/09/2017.

GIL, A. C. Métodos e técnicas de pesquisa social. 5ed. São Paulo: Atlas, 1999. ISBN 85-2242270-2

ROESE, A. D. Agricultura urbana. Embrapa Pantanal, Corumbá, 2003. Disponível em: < http://www.infoteca.cnptia.embrapa.br/infoteca/handle/doc/812707>. Acessado em: 10/09/2017 